\title{
QUEEN'S
UNIVERSITY
BELFAST
}

\section{Does risk of progression from Barrett's esophagus to esophageal adenocarcinoma change based on the number of non-dysplastic endoscopies?}

Kunzmann, A. T., Coleman, H. G., Johnston, B. T., Turkington, R. C., McManus, D., Anderson, L. A., \& Thrift, A. P. (Accepted/In press). Does risk of progression from Barrett's esophagus to esophageal adenocarcinoma change based on the number of non-dysplastic endoscopies? Digestive Diseases and Sciences.

Published in:

Digestive Diseases and Sciences

Document Version:

Peer reviewed version

Queen's University Belfast - Research Portal:

Link to publication record in Queen's University Belfast Research Portal

\section{Publisher rights}

(C) 2020 Springer Nature Switzerland AG. Part of Springer Nature.

This work is made available online in accordance with the publisher's policies. Please refer to any applicable terms of use of the publisher.

\section{General rights}

Copyright for the publications made accessible via the Queen's University Belfast Research Portal is retained by the author(s) and / or other copyright owners and it is a condition of accessing these publications that users recognise and abide by the legal requirements associated with these rights.

Take down policy

The Research Portal is Queen's institutional repository that provides access to Queen's research output. Every effort has been made to ensure that content in the Research Portal does not infringe any person's rights, or applicable UK laws. If you discover content in the

Research Portal that you believe breaches copyright or violates any law, please contact openaccess@qub.ac.uk. 
Does risk of progression from Barrett's esophagus to esophageal adenocarcinoma change based on the number of non-dysplastic endoscopies?

Andrew T Kunzmann ${ }^{1}$, Helen G Coleman ${ }^{1,2}$, Brian T Johnston ${ }^{3}$, Richard C Turkington ${ }^{2,4}$, Damian McManus $^{5}$, Lesley A Anderson ${ }^{1,6}$ \& Aaron P Thrift ${ }^{7,8}$

\section{Affiliations:}

1 Cancer Epidemiology and Health Services Research Group, Centre for Public Health, Queen's University Belfast, Belfast, UK

2 Centre for Cancer Research and Cell Biology, Queen's University Belfast, Belfast, UK

3 Royal Victoria Hospital, Belfast Health \& Social Care Trust, Belfast, UK

4 Belfast City Hospital, Belfast Health \& Social Care Trust, Belfast, UK

5 Department of Pathology, Belfast Health \& Social Care Trust, Belfast, UK

6 Northern Ireland Cancer Registry, Queen's University Belfast, Belfast, UK

7 Section of Epidemiology and Population Sciences, Department of Medicine, Baylor College of Medicine, Houston, Texas, USA

8 Dan L Duncan Comprehensive Cancer Center, Baylor College of Medicine, Houston, Texas, USA

Keywords: Barrett's esophagus; endoscopic surveillance; epidemiology; esophageal adenocarcinoma

Corresponding author: Dr Andrew Kunzmann, Institute of Clinical Sciences Block B, Queen's University Belfast, Royal Victoria Hospital, Belfast, Northern Ireland, BT12 6BA. Phone: +44 (0) 2890635009 Fax: +44 (0) 28 90235900. Email: a.kunzmann@qub.ac.uk

Funding: This study was funded in full by the National Institutes of Health, grant number (NIH P30 DK056338-16). The Northern Ireland Barrett's register was funded by the UK Medical Research Council, Cancer Focus Northern Ireland (formerly the Ulster Cancer Foundation), NI HSC R\&D Office, and Cancer Research UK. The Northern Ireland Cancer Registry is funded by the Public Health Agency. Declaration of conflicting interests: : The Authors declare that there is no conflict of interest 


\section{Acknowledgements}

We express our appreciation to the late Professor Liam Murray, whose contribution to the development of the Northern Ireland Barrett's register and to the field of cancer epidemiology was of great significance. This work uses data provided by patients and collected by healthcare services as part of their care and support. 


\section{ABSTRACT}

Background: There is a large Barrett's esophagus patient population undergoing endoscopic surveillance. Methods to stratify patients into higher and lower risk groups may enable more varied surveillance intervals for patients with non-dysplastic Barrett's esophagus that could optimise use of endoscopy resources.

Objective: We aimed to assess whether risk of progression to esophageal adenocarcinoma differed in patients with multiple endoscopic biopsies negative for dysplasia.

Methods: We conducted a retrospective cohort study among individuals from the population-based Northern Ireland Barrett's register with a histologically confirmed diagnosis of non-dysplastic Barrett's esophagus (with intestinal metaplasia) between 1993 and 2010, who had at least one endoscopic biopsy conducted at least 12 months after diagnosis. We used Poisson regression to estimate incidence rate ratios (IRR) and $95 \%$ confidence intervals $(\mathrm{Cl})$ for the association between number of successive endoscopies showing non-dysplastic Barrett's esophagus and risk of esophageal adenocarcinoma alone, and combined with high-grade dysplasia, at the next endoscopy.

Results: We identified 1,761 individuals who met our eligibility criteria. Subsequent risk of progression to esophageal adenocarcinoma was lower at the next endoscopy following two endoscopies showing non-dysplastic Barrett's esophagus (IRR $0.26,95 \% \mathrm{Cl} 0.10-0.66$ ) than following one endoscopy showing non-dysplastic Barrett's esophagus. Similar findings were apparent for risk of progression to esophageal adenocarcinoma or high-grade dysplasia (IRR 0.41, 95\% Cl 0.22-0.79).

Conclusion: The lower risk of malignant progression in individuals with persistent non-dysplastic Barrett's esophagus over two consecutive endoscopic biopsies but not for longer term persistence does not support hypotheses of persistence being an indicator of less biologically aggressive lesions. Instead, the initial difference may be attributable to post-endoscopy cancers and support the necessity of adhering to robust quality standards for endoscopic procedures. 
Key Summary:

1. Summarise the established knowledge on this subject

- Stratification based on absolute risk of progression to esophageal adenocarcinoma may help to tailor surveillance frequency and optimise use of limited endoscopic capacity.

- However, there are mixed results from previous studies assessing whether risk of progression to esophageal adenocarcinoma or dysplasia differs according to the number of successive endoscopies with biopsies showing NDBE

2. What are the significant and/or new findings of this study?

- Using population based data on histologically confirmed Barrett's esophagus, we found that persistence of NDBE at the first surveillance endoscopy was associated with lower risk of progression to esophageal adenocarcinoma at their next endoscopy.

- However, risk of progression was not reduced after persistence of NDBE over more surveillance endoscopies. 


\section{INTRODUCTION}

Barrett's esophagus is an established pre-malignant condition of the esophagus that increases risk of esophageal adenocarcinoma. The American Gastroenterology Association and British Society of Gastroenterology recommend that individuals with non-dysplastic Barrett's esophagus (NDBE) receive endoscopic surveillance every 3 to 5 years in order to aid early diagnosis and treatment for dysplasia or cancer $(1,2)$. As such, there is an increasingly large Barrett's esophagus patient population undergoing endoscopic surveillance(3). However, the cost-effectiveness of endoscopic surveillance for NDBE patients has been questioned $(4,5)$. Stratification based on absolute risk of progression to esophageal adenocarcinoma may help to tailor surveillance frequency and optimise use of limited endoscopic capacity.

One potential stratification method could be based on NDBE persistence at multiple endoscopies. A recent study by Peters et al found that risk of progression to esophageal adenocarcinoma or highgrade dysplasia was reduced in individuals with persistent NDBE within a population-based cohort (6). However, prior evidence has been mixed (7-9). Studies looking at incidence of esophageal cancer in NDBE patients have indicated a uniform rate of progression over time $(10,11)$; however, these studies did not separate individuals with persistent NDBE from those who have no subsequent endoscopy or who progress to dysplasia.

Therefore, further evidence assessing the potential of persistent NDBE in identifying lower risk patients is required. Most evidence published to date has used follow-up until last oesophagogastroduodenoscopy (hereafter referred to as endoscopy) $(7,8,12)$, which leads to overlapping follow-up periods between groups. It may be more informative and clinically relevant to assess rate of progression at each endoscopic interval, as this more directly informs how many progressions are likely to be detected if surveillance is continued.

We aimed to investigate whether risk of progression to esophageal adenocarcinoma or dysplasia differs according to the number of successive endoscopies with biopsies showing NDBE. We used the 
population-based Northern Ireland Barrett's register (NIBR), which has complete long-term follow-up of a well characterized Barrett's esophagus population (3).

\section{METHODS}

\section{STUDY POPULATION}

The NIBR includes all 13,298 patients diagnosed with Barrett's esophagus in Northern Ireland from January 1993 until December 2010. The methods of the register formation have been previously described (10). Briefly, the register was created by reviewing pathology reports of all esophageal biopsies (corresponding to SNOMED2 codes T62* and SNOMED3 codes T56*) logged in Northern Ireland between 1993 and 2010. A standardised set of guidelines were used for creation of the register, and any pathology reports diagnosing histologically confirmed columnar epithelium of the esophagus, or synonym terms, were deemed to be Barrett's esophagus. Patients under 16 years of age and reports relating to cancer confined to the oesophagogastric junction were excluded. A subset of patients in the NIBR have specialized intestinal metaplasia at biopsy $(\mathrm{N}=5,150)$.

We linked the NIBR to the NI Cancer Registry (NICR) to identify those Barrett's esophagus patients who developed esophageal cancer by the end of 2010. The NICR contains data on all patients diagnosed with cancer in Northern Ireland since 1993. The NICR uses the International Classification of diseases V.10 (ICD10) to classify patient tumour type and location based on accompanying clinical information. ICD10 codes were used to identify patients from the NICR with adenocarcinoma or histologically unspecified tumours of the esophagus. Histologically unspecified tumours were included to ensure complete ascertainment of tumours that may have arisen in patients with Barrett's esophagus. 
The study protocol conforms to the ethical guidelines of the 1975 Declaration of Helsinki as reflected in a priori ethical approval for the NIBR, NICR and related research granted by the regional ethics committee of Northern Ireland (10/NIR01/53, 22 $2^{\text {nd }}$ October 2015). As this is a population-based Cancer Registry study, informed consent is unfeasible but use for research permitted under ethical guidelines due to the strict nature of data confidentiality and the ability to withdraw consent (13). The NICR and NIBR have strict data confidentiality rules which mean that cell counts less than 5 cannot be revealed. As we combine outcomes we were unable to report exact figures less than 10 and cannot report both person-years and incidence rates.

\section{INCLUSION AND EXCLUSION CRITERIA}

For the current study, we first included only those patients in the NIBR with an index Barrett's esophagus diagnosis date until December 2009 to allow 12 months of follow-up (Figure 1). For the primary analysis, patients with an index biopsy histologically diagnosing NDBE with specialized intestinal metaplasia or related terms and at least 1 additional endoscopy with biopsy at least 12 months later (regardless of findings) were included in this study. Dysplasia or esophageal cancer diagnosed within 12 months of the index biopsy were classified as prevalent cases and patients were excluded.

Secondary analyses additionally included NDBE patients without confirmed specialized intestinal metaplasia, to reflect clinical practice in the UK (1).

\section{GROUPING AND OUTCOMES}

Patients were assigned to at least one of five groups (Groups 1 to 5 ) based on the number of endoscopies conducted at least 12 months apart showing NDBE. All 1,761 NDBE patients who met the inclusion criteria were included in Group 1. The follow-up period for Group 1 started at their index endoscopy, with the outcome ascertained at their subsequent endoscopy conducted at least 12 months later. Patients diagnosed with esophageal adenocarcinoma or dysplasia, or those without further endoscopies were not included in subsequent groups. Patients with NDBE at the outcome 
endoscopy for Group 1 (usually their second endoscopy), who also had another subsequent endoscopy at least 12 months later, were included in Group 2. To avoid overlapping follow-up periods, follow-up for Group 2 started from the date of the Group 1 outcome endoscopy until their subsequent endoscopy at least 12 months later. The same pattern of eligibility and non-overlapping follow-up periods were used for subsequent groups. Therefore eligibility for Group 5 required NDBE to be demonstrated in at least 5 consecutive endoscopies (including their index endoscopy), with the outcome assessed at their subsequent endoscopy. All participants included in Group 5 were also included in Groups 1 to 4, but follow-up periods for each group did not overlap.

Multiple endoscopies conducted within 12 months may reflect uncertain diagnoses after the initial endoscopy, so were classed as one endoscopy using the date of the first endoscopy and the most advanced histological diagnosis. Patients were considered to have high-grade dysplasia, if the pathologist reported "high-grade" or "severe" dysplasia in the endoscopic biopsy sample.

\section{STATISTICAL ANALYSIS}

The median duration of follow-up was calculated for each group. Poisson regression models were used to calculate incidence rates, rate ratios, and corresponding $95 \%$ confidence intervals $(\mathrm{Cl})$ for four outcomes (i) esophageal adenocarcinoma, (ii) esophageal adenocarcinoma or high-grade dysplasia, (iii) esophageal adenocarcinoma or any dysplasia, and (iv) dysplasia, according to group (I.e. number of endoscopies showing NDBE). The length of esophageal adenocarcinoma time period contributed to the Poisson model "offset" variable. We used the exchangeable working correlation structure to account for the correlation among repeated observations for the same subject, after creating multiple records for esophageal adenocarcinoma subject by period. Analyses adjusted for age at index endoscopy, sex and year of index endoscopy (to account for changes in incidence over time).

Sensitivity analyses also assessed whether the associations differed when using the broader UK definition of BE; and by age; period of qualifying endoscopy; and gender. A priori sensitivity/secondary analyses assessed if the results were consistent when follow-up was continued until last endoscopy 
or first diagnosis of esophageal adenocarcinoma or high-grade dysplasia. Esophageal adenocarcinoma tumour stage was compared between groups using chi-squared tests.

Analyses were conducted using Stata/IC statistical software (version 14.1, College Station, TX, USA).

\section{RESULTS}

The overall study cohort for the primary analysis included 1,761 patients with histologically confirmed Barrett's esophagus with intestinal metaplasia and no dysplasia or cancer reported at baseline or within 12 months.

Individuals with more consecutive endoscopies showing NDBE were more likely to be male, younger aged at their index endoscopy and diagnosed in the earlier years of the registry than individuals with fewer consecutive endoscopies showing NDBE (Table 1).

Subsequent risk of progression to esophageal adenocarcinoma, at the next endoscopy, was significantly lower after two consecutive endoscopies showing NDBE (IRR 0.26, 95\% $\mathrm{Cl} 0.10-0.66$ ) than after one endoscopy showing NDBE (Table 2). Similar findings were observed for risk of progression to esophageal adenocarcinoma or high-grade dysplasia combined (IRR $0.41,95 \% \mathrm{Cl} 0.22-0.79$, Table 2 Figure 2) and for risk of progression to esophageal adenocarcinoma or any dysplasia (IRR $0.69,95 \% \mathrm{Cl}$ 0.51-0.92). However, risk of progression was not reduced in subsequent groups with more prior endoscopies showing NDBE, except for group 4 who had a reduced risk of esophageal adenocarcinoma or dysplasia (IRR $0.42,95 \% \mathrm{Cl} 0.21-0.87$ ) and dysplasia only (IRR $0.40,95 \% \mathrm{Cl} 0.17-0.91$ ) compared to group 1.

The reduced risk of progression in group 2 was also apparent when using a broader definition of Barrett's esophagus which includes patients regardless of the presence of specialized intestinal metaplasia (IRR 0.38, 95\% Cl: 0.19-0.77). The association was also apparent when limited to men (IRR 
$0.31,95 \% \mathrm{Cl}: 0.11-0.89)$ and patients aged over 60 at their index endoscopy (IRR $0.08,95 \% \mathrm{Cl} 0.01-$

0.56). The association was weaker, and not statistically significant when follow-up for esophageal adenocarcinoma group was continued until their last endoscopy or progression, as used in previous studies (Table 3).

\section{DISCUSSION}

In this population-based study of histologically confirmed Barrett's esophagus patients, we found that patients with two endoscopies showing NDBE, compared to NDBE on one endoscopy, had an almost 4 times lower risk of progression to esophageal adenocarcinoma at their next endoscopy. Smaller reductions were also apparent when "progression" additionally included HGD or any dysplasia. Results for patients with persistent NDBE at a greater number of endoscopies were less clear.

It has been suggested that surveillance intervals in patients with Barrett's esophagus, often between 3-5 years depending on country $(1,14)$, could be lengthened in patients at a lower risk of progression to esophageal adenocarcinoma or dysplasia to optimise use of limited endoscopic capacity (12). Our study, conducted within a population with recommended surveillance intervals between 2-3 years, indicates that patients with persistent NDBE at the first surveillance endoscopy were at lower risk of subsequent progression to esophageal adenocarcinoma or dysplasia in between endoscopies. This result is consistent with previous findings using histologically confirmed NDBE diagnoses from the US by Gaddam et al (12) and the Netherlands by Peters et al (8), despite differences in methodological approach (described in the strengths and limitations section). Results differed in a prior study (9) without histological confirmation of NDBE status, though this may be due to selection bias of high risk patients, as evidenced by shorter intervals between successive endoscopies. Therefore, a reduced risk of progression following NDBE persistence at the first surveillance endoscopy has been noted across robust studies. 
The evidence is less clear for individuals with persistent NDBE over a greater number of endoscopies. Risk of progression to esophageal adenocarcinoma in individuals with persistent NDBE over the greatest number of endoscopies (group 5) were at a similar risk of progression to individuals in the reference group, though low numbers preclude firm conclusions. In terms of progression to esophageal adenocarcinoma or dysplasia of any grade, which had a larger number of events, a more linear trend over groups is apparent and risk of progression was lower in patients with persistent NDBE at their third surveillance endoscopy. The corresponding findings from Peters et al (6) are similarly mixed, despite consistent results for patients with persistent NDBE at the first surveillance endoscopy. Whilst risk of progression reduced with persistent NDBE over a greater number of endoscopies when applying a 1 year interval between endoscopies, risk of progression increased with NDBE persistence when applying shorter interval criteria ( $<1$ year).

It is possible that the mixed results in the current study are attributable to reduced statistical power as the number of events was low and selection bias towards higher risk patients for continued surveillance (though the similar follow-up periods between groups are reassuring). The reduced risk of progression following two consecutive endoscopic biopsies displaying NDBE could be attributable, in part, to a reduced risk of post-endoscopy cancers. It has been estimated from the NIBR and in other cohorts $(15,16)$ that $\sim 10 \%$ of esophageal adenocarcinomas may be post-endoscopy cancers some of which may have been present but undetected at the first endoscopic biopsy. These false-negative lesions may inflate the progression rate in the first group as they are more likely to be detected at the first surveillance endoscopy, whereas fewer false-negatives are likely to be present at subsequent endoscopies. Therefore, these mixed results may highlight the challenges faced in detecting malignant lesions at the initial index endoscopy and the need to adhere to robust quality standards (17), published after the study period. Similarly, early repeat endoscopy, if the index endoscopy does not meet quality standards in terms of visualisation or biopsy protocol, may be beneficial to reduce postendoscopy lesions (17). 
The subsequent pattern of results does not offer strong support for the hypothesis that persistent NDBE reflects more stable, less biologically aggressive disease, and instead may indicate a steady rate of progression, which is consistent with findings based on clonal diversity $(18,19)$ and studies looking at progression over time (10). Similarly, when using follow-up from the qualifying endoscopy for each group until either the outcome developed or the last endoscopy recorded within the study period (rather than the next endoscopy), no reductions in risk of progression were apparent in patients with persistent NDBE.

Whilst it is possible that dysplasia/cancer diagnosis increased over time as prevalence of risk factors like obesity may have changed, we adjusted for cohort effects through year of BE diagnosis and prior analyses from other UK cohorts didn't find evidence of time period effects as incidence of dysplasia/cancer in surveillance endoscopies was stable over time (1995-2009) (World J Gastroenterol. 2016 Dec 28; 22(48): 10592-10600).

\section{Strengths \& limitations}

In addition to the robust methodology, this study had a number of strengths. The cohort is from a population-based register, enabling capture of all cancers and histologically confirmed Barrett's esophagus cases in a defined area, with low migrations rates (20). Additionally, intervals between endoscopies remained constant across each group suggesting that high-risk patients were not preferentially selected for more regular endoscopic surveillance, though as indicated earlier may have been selected for longer term surveillance. Unlike previous studies that calculated risk of progression over the remaining follow-up period, our primary analysis calculated risk at the next endoscopy to avoid overlapping follow-up periods between groups, and to better quantify the likelihood of detecting esophageal adenocarcinoma at each subsequent endoscopy. Our study also avoided using mutually exclusive selection, unlike a previous study (7), to reduce risk of inflating progression in the non-persistent NDBE group by excluding non-progressors eligible for later groups.

There are also some potential limitations to consider. The statistical power to detect differences between groups 3-5 and group 1 was limited, which prevents firm conclusions regarding the incidence 
in these patients. The follow-up period was limited due to availability of data on subsequent endoscopies after 2010. Since the study includes data between 1993 and 2010, it is possible that the data reflects historic endoscopic practices and that patterns of post-endoscopy lesions may have changed following changes to endoscopic guidelines and quality standards (15). Adherence to protocols may have changed over time, which could lead to improved detection in later groups, though unfortunately information on adherence was not available. Nevertheless, the results of the current study reflect real world practices and prior evidence suggests that rates of post-endoscopy cancers in the NIBR did not change between 1993 and 2013 (15). Similarly patterns of dysplasia diagnosis may have changed, or since the study period due to the introduction of endoscopic mucosal resection and radiofrequency ablation.

Information on Barrett's segment length was not always available, which meant stratification based on Barrett's length was not possible, which is a limitation given that risk of progression is known to be higher in long-segment Barrett's $(10,21)$.

Risk of progression may be influenced by age, time of outcome assessment (period) or time of BE diagnosis (cohort). We were able to adjust for age and time of diagnosis, however, as we needed to offset by person-years, we were unable to additionally adjust for time of outcome assessment. Therefore, the later time period of outcome endoscopies in later groups could partially explain the lack of a reduced risk of progression. Nevertheless prior analyses in other UK Barrett's esophagus cohorts didn't indicate time period effects between 1995-2005 (21).

The proportion of NDBE patients with at least 1 year of endoscopic follow-up with biopsy was low ( 37\%), in part due to limited follow-up time available for individuals diagnosed post-2007. This may lead to selection bias due to symptomatic presentation as information on reason for endoscopy was unavailable. The selection bias may primarily impact the non-persistent NDBE group, as nonsurveillance attenders who do not progress and do not undergo endoscopy would have been excluded, whereas non-surveillance attenders who progress and had an endoscopy for symptomatic 
presentation would have been included. We attempted to limit the impact of symptomatic presentation by conducting a sensitivity analysis excluding individuals with over 5 years of follow-up between endoscopies, which did not materially change the estimates and may alleviate these concerns.

\section{Conclusion}

This study adds to the body of evidence suggesting that in patients with persistent NDBE at their first surveillance endoscopy, risk of subsequent progression to esophageal adenocarcinoma or dysplasia in between surveillance endoscopies is lower. However, the evidence for a reduced risk of progression, in patients with persistent NDBE over a greater number of endoscopies is less clear. Further evidence will likely be required before recommendations to extend surveillance intervals for subsequent surveillance periods can be supported. The high incidence at the first surveillance endoscopy, may be indicative of undetected lesions at the initial index endoscopy, which indicates the need for highquality endoscopies to reduce risk of post-endoscopic lesions . 


\section{REFERENCES}

1 Fitzgerald RC, Di Pietro M, Ragunath K, et al. British Society of Gastroenterology guidelines on the diagnosis and management of Barrett's oesophagus. Gut 2014;63:7-42.

2 Shaheen NJ, Falk GW, Iyer PG, et al. ACG Clinical Guideline: Diagnosis and Management of Barrett's Esophagus. Am J Gastroenterol 2016;111:30-50.

3 Coleman HG, Bhat S, Murray L, et al. Increasing incidence of Barrett's oesophagus: a population-based study. Eur J Epidemiol 2011;26:739-45.

4 Hirst NG, Gordon LG, Whiteman DC, et al. Is endoscopic surveillance for non-dysplastic Barrett's esophagus cost-effective? Review of economic evaluations. J Gastroenterol Hepatol 2011;26:247-54.

5 Gordon LG, Mayne GC, Hirst NG, et al. Cost-effectiveness of endoscopic surveillance of nondysplastic Barrett's esophagus. Gastrointest Endosc 2014;79:242-256.e6.

6 Peters $\mathrm{Y}$, Honing J, Kievit W, et al. Incidence of Progression of Persistent Non-Dysplastic Barrett's Esophagus to Malignancy. Clin Gastroenterol Hepatol Published Online First: 10 September 2018.

7 Krishnamoorthi R, Ramos GP, Crews N, et al. Persistence of Nondysplastic Barrett's Esophagus Is Not Protective Against Progression to Adenocarcinoma. Clin Gastroenterol Hepatol 2017;15:950-2.

8 Peters Y, Honing J, Kievit W, et al. 535 Incidence of Malignant Progression in Persistent Nondysplastic Barrett's Esophagus, a Dutch Nationwide Cohort Study. In: Gastrointestinal Endoscopy. Elsevier 2017. AB76.

9 Nguyen T, Thrift AP, Yu X, et al. The Annual Risk of Esophageal Adenocarcinoma Does Not Decrease Over Time in Patients With Barrett's Esophagus. Am J Gastroenterol 2017;112:104955. 

patients: results from a large population-based study. J Nat/ Cancer Inst 2011;103:1049-57.

11 Hvid-Jensen F, Pedersen L, Drewes AM, et al. Incidence of adenocarcinoma among patients with Barrett's esophagus. N Engl J Med 2011;365:1375-83.

12 Gaddam S, Singh M, Balasubramanian G, et al. Persistence of nondysplastic Barrett's esophagus identifies patients at lower risk for Esophageal Adenocarcinoma: Results from a large multicenter cohort. Gastroenterology 2013;145:548-553.e1.

13 Storm H, Brewster D, Coleman M, et al. Guidelines on confidentiality for population-based cancer registration. Eur. J. Cancer Prev. 2005;14:309-27.

14 Shaheen NJ, Falk GW, Iyer PG, et al. ACG Clinical Guideline: Diagnosis and Management of Barrett's Esophagus. Am J Gastroenterol 2016;111:30-50.

15 van Putten M, Johnston BT, Murray L, et al. 'Missed' oesophageal adenocarcinoma and highgrade dysplasia in Barrett's oesophagus patients: A large population-based study. United Eur Gastroenterol J 2018;6:519-28.

16 Menon S, Trudgill N. How commonly is upper gastrointestinal cancer missed at endoscopy? A meta-analysis. Endosc Int open 2014;2:E46-50.

17 Beg S, Ragunath K, Wyman A, et al. Quality standards in upper gastrointestinal endoscopy: a position statement of the British Society of Gastroenterology (BSG) and Association of Upper Gastrointestinal Surgeons of Great Britain and Ireland (AUGIS). Gut 2017;66:1886-99. risk in Barrett's oesophagus. Nat Commun 2016;7:12158.

19 Li X, Galipeau PC, Paulson TG, et al. Temporal and Spatial Evolution of Somatic Chromosomal Alterations: A Case-Cohort Study of Barrett's Esophagus. Cancer Prev Res 2014;7:114-27. 
20 Northern Ireland Statistics and Research Agency. Long-term International Migration Statistics for Northern Ireland ( 2016 ). 2017.

21 Coleman HG, Bhat SK, Murray L, et al. Symptoms and Endoscopic Features at Barrett's Esophagus Diagnosis: Implications for Neoplastic Progression Risk. Am J Gastroenterol 2014;109:527-34. 
Table 1. Participant characteristics by group

\begin{tabular}{lccccc}
\hline & $\begin{array}{c}\text { Group 1 } \\
(\mathrm{n}=1761)\end{array}$ & $\begin{array}{c}\text { Group 2 } \\
(\mathrm{n}=840)\end{array}$ & $\begin{array}{c}\text { Group 3 } \\
(\mathrm{n}=399)\end{array}$ & $\begin{array}{c}\text { Group 4 } \\
(\mathrm{n}=173)\end{array}$ & $\begin{array}{c}\text { Group 5 } \\
(\mathrm{n}=88)\end{array}$ \\
\hline Age at NDBE diagnosis (mean) & 58.44 & 57.03 & 56.79 & 55.03 & 54.14 \\
Men (\%) & $65.0 \%$ & $65.6 \%$ & $67.3 \%$ & $71.2 \%$ & $73.3 \%$ \\
$\begin{array}{l}\text { Mean calendar year of NDBE } \\
\text { diagnosis }\end{array}$ & 2000 & 1998 & 1997 & 1996 & 1995 \\
$\begin{array}{l}\text { Mean calendar year of } \\
\text { qualifying endoscopy }{ }^{1} \text { of }\end{array}$ & 2000 & 2000 & 2001 & 2001 & 2002 \\
$\begin{array}{l}\text { Median years follow-up until } \\
\text { next endoscopy }\end{array}$ & 1.98 & 2.01 & 1.99 & 1.91 & 1.96 \\
$\begin{array}{l}1 \\
\text { Start of follow-up period in each group. }\end{array}$ & & & &
\end{tabular}

Group number reflects number of endoscopies (more than 12 months apart) showing non-dysplastic Barrett's esophagus. 
Table 2. Incidence rate and incidence rate ratios of progression by number of prior upper endoscopies showing NDBE.

\begin{tabular}{|c|c|c|c|c|}
\hline & $\begin{array}{l}\text { Total number of } \\
\text { NDBE patients }\end{array}$ & $\begin{array}{l}\text { Number of } \\
\text { progressors }\end{array}$ & $\begin{array}{c}\text { Incidence rate } \\
\text { per } 100 \mathrm{PY}\end{array}$ & $\begin{array}{l}\text { Adjusted }^{1} \\
\text { IRR }(95 \% \text { CI) }\end{array}$ \\
\hline \multicolumn{5}{|c|}{ Esophageal adenocarcinoma } \\
\hline Group $1^{2}$ & 1761 & 42 & 1.02 & 1.00 (Referent) \\
\hline Group 2 & 840 & $<10^{3}$ & 0.27 & $0.26(0.10-0.66)$ \\
\hline Group 3 & 399 & $<10$ & 0.72 & $0.65(0.27-1.56)$ \\
\hline Group 4 & 173 & $<10$ & 0.61 & $0.53(0.12-2.24)$ \\
\hline Group 5 & 88 & $<10$ & 1.22 & $1.04(0.24-4.50)$ \\
\hline \multicolumn{5}{|c|}{ Esophageal adenocarcinoma/HGD } \\
\hline Group 1 & 1761 & 60 & 1.45 & 1.00 (Referent) \\
\hline Group 2 & 840 & 11 & 0.59 & $0.41(0.22-0.79)$ \\
\hline Group 3 & 399 & 10 & 1.20 & $0.82(0.41-1.63)$ \\
\hline Group 4 & 173 & $<10$ & 0.61 & $0.41(0.10-1.71)$ \\
\hline Group 5 & 88 & $<10$ & 1.22 & $0.83(0.20-3.51)$ \\
\hline \multicolumn{5}{|c|}{ Esophageal adenocarcinoma/Dysplasia } \\
\hline Group 1 & 1761 & 179 & 4.34 & 1.00 (Referent) \\
\hline Group 2 & 840 & 60 & 3.22 & $0.69(0.51-0.92)$ \\
\hline Group 3 & 399 & 35 & 4.20 & $0.81(0.56-1.17)$ \\
\hline Group 4 & 173 & $<10$ & 2.44 & $0.42(0.21-0.87)$ \\
\hline Group 5 & 88 & $<10$ & 2.44 & $0.41(0.15-1.11)$ \\
\hline \multicolumn{5}{|l|}{ Dysplasia } \\
\hline Group 1 & 1761 & 137 & 3.32 & 1.00 (Referent) \\
\hline Group 2 & 840 & 55 & 2.95 & $0.81(0.59-1.11)$ \\
\hline Group 3 & 399 & 29 & 3.48 & $0.86(0.57-1.30)$ \\
\hline Group 4 & 173 & $<10$ & 1.83 & $0.40(0.17-0.91)$ \\
\hline Group 5 & 88 & $<10$ & 1.22 & $0.25(0.06-1.04)$ \\
\hline
\end{tabular}

${ }^{1}$ Poisson model adjusted for age at $\mathrm{BE}$ diagnosis, sex and year of $\mathrm{BE}$ diagnosis

${ }^{2}$ Group number reflects number of endoscopies (more than 12 months apart) showing non-dysplastic Barrett's esophagus.

${ }^{3}$ Small numbers reported as $<10$ to avoid disclosing cell counts $<5$ for data confidentiality purposes. Abbreviations: HGD: High-grade dysplasia; IR: Incidence rate; IRR: Incidence rate ratio; Person-years: PY. 
Table 3. Adjusted ${ }^{1}$ incidence rate ratios by group based on sensitivity analyses

\begin{tabular}{|c|c|c|c|c|c|c|}
\hline & & Group $1^{2}$ & Group 2 & Group 3 & Group 4 & Group 5 \\
\hline \multirow{2}{*}{ UK definition } & $\mathrm{N}$ & 2541 & 1133 & 524 & 222 & 112 \\
\hline & IRR & 1.00 (Referent) & 0.38 (0.19-0.77) & $0.55(0.23-1.30)$ & $0.44(0.11-1.85)$ & $1.32(0.40-4.40)$ \\
\hline \multirow{2}{*}{ Men only } & $\mathrm{N}$ & 1146 & 552 & 268 & 124 & 65 \\
\hline & IRR & 1.00 (Referent) & $0.31(0.11-0.89)$ & $0.48(0.14-1.62)$ & $0.37(0.05-2.81)$ & $0.72(0.09-5.55)$ \\
\hline \multirow{2}{*}{ Under 60 at index } & $\mathrm{N}$ & 930 & 471 & 224 & 107 & 54 \\
\hline & IRR & 1.00 (Referent) & 0.67 (0.21-2.10) & $1.06(0.28-3.97)$ & 0.77 (0.09-6.37) & Not calculable \\
\hline \multirow{2}{*}{ Over 60 at index } & $\mathrm{N}$ & 831 & 369 & 175 & 66 & 34 \\
\hline & IRR & 1.00 (Referent) & 0.08 (0.01-0.56) & 0.47 (0.14-1.59) & $0.42(0.06-3.16)$ & $1.58(0.36-7.06)$ \\
\hline \multirow{2}{*}{ Diagnosis pre-2000 } & $\mathrm{N}$ & 991 & 347 & 89 & 14 & $<10$ \\
\hline & IRR & 1.00 (Referent) & $0.39(0.09-1.72)$ & $2.32(0.65-8.29)$ & Not calculable & Not calculable \\
\hline \multirow{2}{*}{ Interval $<5$ years } & $\mathrm{N}$ & 1651 & 809 & 386 & 172 & 88 \\
\hline & IRR & 1.00 (Referent) & $0.33(0.10-1.11)$ & $1.19(0.43-3.29)$ & $1.23(0.27-5.63)$ & $2.53(0.54-11.90)$ \\
\hline \multirow{2}{*}{ Follow-up until last EGD } & $\mathrm{N}$ & 1761 & 840 & 399 & 173 & 88 \\
\hline & IRR & 1.00 (Referent) & $0.91(0.75-1.10)$ & $0.90(0.70-1.16)$ & $0.90(0.63-1.28)$ & $0.89(0.55-1.42)$ \\
\hline
\end{tabular}

${ }^{1}$ Poisson model adjusted for age at BE diagnosis, sex and year of BE diagnosis

${ }^{2}$ Group number reflects number of endoscopies (more than 12 months apart) showing non-dysplastic Barrett's esophagus. 


\section{Figure legends}

Figure 1. Flow chart of participant selection

Abbreviations: NDBE: Non-dysplastic Barrett's esophagus; NIBR=Northern Ireland Barrett's Register.

Figure 2. Adjusted incidence rate ratios and 95\% confidence intervals for progression from NDBE to esophageal adenocarcinoma or high-grade dysplasia by number of prior upper endoscopies showing NDBE.

${ }^{1}$ Poisson model adjusted for age at BE diagnosis, sex and year of BE diagnosis

${ }^{2}$ Group number reflects number of endoscopies (more than 12 months apart) showing non-dysplastic Barrett's esophagus. Outcome assessed at subsequent endoscopy at least 12 months later. Group 1, from index endoscopy showing NDBE is the reference category.

${ }^{3}$ Patients included in later groups were also included in previous groups. 